\title{
ALGUNOS EJEMPLOS DE INFLUENCIA MODERNISTA EN LA GENERACIÓN DEL 70
}

\author{
Joaquín Moreno Pedrosa
}

Resumen: En la literatura española de posguerra, los poetas conocidos como "novísimos" y "generación del 70" han reivindicado de modo muy particular la influencia del Modernismo. Esta influencia puede verse en su concepción de la poesía, como una actividad en la que los aspectos técnicos son esenciales, comportando cierta ironía y la construcción de una identidad. Además, los poetas del 70 son herederos de los modernistas en sus prácticas métricas, particularmente en lo que se refiere a la rima y al uso del verso alejandrino.

Palabras clave: Poesía, Modernismo, Generación del 70, Antonio Carvajal, Pere Gimferrer, Miguel d'Ors.

\begin{abstract}
In Spanish literature after the civil war, poets known as "novísimos" and "generation of 1970" especially claim influence of the Modernism. It can be seen in their conceivement of Poetry as an activity in which technic sides are essential, while involving construction of identity and irony. Besides, poets of 70's are heirs of modernists in their metrical practice, especially concerning rhyme and alexandrine verse.
\end{abstract}

Key words: Poetry, Modernism, Generation of 1970, Antonio Carvajal, Pere Gimferrer, Miguel d'Ors. 

A valoración del Modernismo en el estudio de la poesía española posterior a la guerra civil es con frecuencia amrarios, especialmente de carácter moral e ideológico, ha llevado con frecuencia a repudiar los modelos modernistas. Por otro, este repudio pertenece exclusivamente al plano crítico y teórico, y está de hecho desmentido por la práctica de los poetas más significativos desde 1939. En la generación de posguerra (en la que incluimos, con independencia de su orientación estética, a todos los autores nacidos entre 1909 y 1923), los ejemplos de Blas de Otero y José Hierro nos proporcionan abundantes muestras de experimentación métrica y estilística, que revelan su entronque con la renovación de los lenguajes poéticos llevada a cabo por el Modernismo. Pero el ejemplo más evidente de influencia modernista en esta generación se encuentra, sin duda, en los autores del grupo Cántico, de Córdoba. Guillermo Carnero ha acertado plenamente al caracterizar la poesía de estos autores como un «intimismo de contenido culturalista, heredado del Modernismo y los poetas del $27 »^{1}$, pues tal será, en el panorama poético de la posguerra, su rasgo más representativo.

Como han señalado varios estudiosos ${ }^{2}$, los poetas de la generación del 50 (nacidos entre 1924 y 1938) vuelven a resaltar el aspecto formal y artificioso de la obra literaria como rasgo esencial de su naturaleza, marcando el fin de la poética social. Además, los poetas del 50 prefiguran muchos de los rasgos con los que posteriormente se caracterizará a la generación del 70,

\footnotetext{
"Guillermo Carnero, El grupo "Cántico" de Córdoba, Editora Nacional, Madrid, 1976, p. 41.

2 Vid., por ejemplo, Pedro Provencio, "La generación del 70", Cuadernos Hispanoamericanos $\mathrm{n}^{\circ} 522,1993$, p. 89; Juan José Lanz, Antología de la poesía española (1960-1975), Espasa-Calpe, Madrid, 1997, p. 14.
} 
rasgos que poseen una evidente filiación modernista. Por ejemplo, Elena Barroso ha manifestado cómo, de modo especialmente característico, la lección de Cántico ha calado entre los poetas andaluces de esta generación, en cuya obra se realiza «una síntesis de vitalismo, sensualidad y actitud meditativa», no exenta de referencias culturalistas y cierto barroquismo expresivo ${ }^{3}$. Luis Jiménez Martos, en su antología Nuevos poetas españoles, aprecia en estos autores una línea de continuidad con la poética precedente, pero también «un regreso al individualismo; más aún, al intimismo», y «una equidistancia entre el formalismo y el prosaísmo», cobrando importancia el argumento o la anécdota, sin empobrecimiento del lenguaje ${ }^{4}$. En su trabajo sobre la influencia de Luis Cernuda en la obra de estos autores, María Victoria Utrera subraya, sobre todo en Gil de Biedma, la importancia concedida a la experiencia personal, así como «la forma particular de construir el personaje poético gracias a las técnicas de distanciamiento» ${ }^{5}$. Por último, José Luis García Martín ha destacado la abundancia de «momentos metapoéticos» en la obra de esos autores, así como el culturalismo presente en los poemas de Gil de Biedma, Fernando Quiñones, María Victoria Atencia y Juan José Cuadros ${ }^{6}$.

La muestra más evidente de continuidad entre estos poetas y la generación del 70 nos la proporciona la Antología de la nueva poesía española de José Batlló ${ }^{7}$. Como puede verse en sus páginas, la obra de estos autores comparte la misma manera de enfrentarse al poema como hecho estrictamente lingüístico. Si hubo alguna ruptura en la poesía de esos años, ésta fue, como dice Lanz, la que «producían la generación del 50 y los poetas más jóvenes con la poesía anterior» ${ }^{8}$, la que se concebía según una poética de influencia marxista.

\footnotetext{
${ }^{3}$ Elena Barroso, Poesía andaluza de hoy (1950-1990), Biblioteca de Cultura andaluza, Sevilla, 1991, pp. 18-19.

${ }^{4}$ Luis Jiménez Martos, Nuevos poetas españoles, Ágora, Madrid, 1961, pp. 13-15.

${ }^{5}$ María Victoria Utrera, "Luis Cernuda en la poesía española del siglo XX", en VV. AA., A zaga de tu huella. Homenaje al profesor Cristóbal Cuevas, Universidad de Málaga, Málaga, 2005, vol. II, p. 137, nota al pie.

${ }^{6}$ José Luis García Martín, La segunda generación de posguerra, p. 107; sobre el culturalismo, pp. 209-210.

${ }^{7}$ Ciencia Nueva, col. El bardo, Madrid, 1968.

${ }^{8}$ Juan José Lanz, op. cit., p. 48.
} 
La presencia del Modernismo es, pues, constante en las generaciones de posguerra. Pero serán los poetas de la generación del 70 (nacidos entre 1939 y 1953) quienes reivindiquen de forma más explícita los modelos modernistas. Así, por ejemplo, la nómina de autores que integran el "culturalismo" del grupo de los "novísimos", tal como la ha trazado César Nicolás, comprende a autores españoles, como Góngora y los barrocos menores, modernistas como Valle-Inclán, Darío o Manuel Machado, los poetas del 27, las vanguardias y el surrealismo hasta Edmundo de Ory, el grupo "Cántico"; sudamericanos, como Octavio Paz, Lezama Lima o Borges; y de otras tradiciones literarias, desde los grecolatinos hasta trovadores provenzales y poetas medievales, los grandes románticos alemanes e ingleses (Blake, Byron, Keats, Shelley, Coleridge, Novalis y Hölderlin), los simbolistas y malditos del XIX (Baudelaire, Poe, Rimbaud, Mallarmé), Ezra Pound, T. S. Eliot, Wallace Stevens, hasta manifestaciones artísticas contemporáneas, del pop, el underground, el cine, los tebeos, la música, etc, integrados con «una sensibilidad peculiar, actual y sincrética» ${ }^{9}$. Además de la mención expresa de los modernistas españoles, muchos de los autores incluidos en esta lista fueron a su vez modelos para el Modernismo español, como los románticos alemanes e ingleses y los simbolistas franceses.

Además de este cosmopolitismo en sus influencias y modelos literarios, muchos poetas de la generación del 70 presentan también en su obra otras características que entroncan con el estilo del Modernismo. Así, José Olivio Jiménez ha resumido los rasgos más característicos de esta poesía, desde la aparición de los primeros libros de la generación del 70, entre 1966 y 1967, hasta 1975. Tomando como referencia a Antonio Carvajal, Marcos Ricardo Barnatán, Jenaro Talens, José Miguel Ullán, Fernando Millán, Jesús García Sánchez y Pureza Canelo, esos rasgos serían los siguientes:

\footnotetext{
9 César Nicolás, “Novísimos (1966-1988): notas para una poética”, Ínsula n505, enero de 1989, p. 13. Respecto a estos últimos elementos, conformadores de lo que se ha llamado camp, Juan José Lanz ha señalado cómo, ya en 1971 habían desaparecido prácticamente por completo (Juan José Lanz, "La renovación de la poesía española en los años sesenta y la generación del 68”, en Juan José Lanz, La llama en el laberinto. Poesía y poética en la generación del 68, Editora Regional de Extremadura, Mérida, 1994, p. 60).
} 
-Un deleitoso apurar la belleza autónoma de la palabra, preciosismo verbal, un neomodernismo asumido irónicamente.

-Impregnación en el lenguaje de las posibilidades sugerentes del irracionalismo poético.

-El gusto por incorporar al poema el dato de cultura, el culturalismo.

-Ardua vigilancia sobre una palabra que se quiere esencial y tensa, depurada y concisa.

-Cierto hermetismo crítico, un código muy personal y aun crítptico del lenguaje.

-Un afanoso designio de experimentación radical.

-La indagación de la poesía dentro del texto poético.

-Una fina veta de lirismo ahondador, nunca del todo ausente.

-Los nombres y temas (y aun técnicas) tomadas del cine, la radio, la televisión.

-El deseo de configurar muchos de ellos la imagen del escritor total, con incursiones en otros géneros literarios, la crítica literaria y el ensayo ${ }^{10}$.

Los mismos poetas del 70 han dejado constancia de su deuda con el movimiento modernista. Pere Gimferrer, recopilador de una Antología de la poesía modernista, afirma que dicha antología es «un testimonio personal, un testimonio de época, el testimonio de los gustos de una generación, del momento en que redescubrimos el modernismo $\gg{ }^{11}$. Del mismo modo, en su antología de la poesía de Rubén Darío, Gimferrer declara que «varias generaciones de lectores hispánicos, entre las que figura la mía propia, han descubierto en Rubén la poesía», declarando al nicaragüense «el poeta más naturalmente dotado que ha tenido el castellano desde Lope de Vega» ${ }^{12}$. Más concretamente, los aspectos de la poesía de Rubén Darío que el poeta catalán encontró más atractivos en su adolescencia fueron su franqueza en el

\footnotetext{
${ }^{10}$ José Olivio Jiménez, "Variedad y riqueza de una estética brillante", Ínsula n505, enero de 1989, p. 2.

${ }^{11}$ Pere Gimferrer, Antología de la poesía modernista, Península, Barcelona, 1981, p. 5.

${ }^{12}$ Pere Gimferrer, "Introducción”, en Rubén Darío, Poesía, introducción y selección de Pere Gimferrer, Planeta, Barcelona, 1987, p. xv.
} 
tratamiento de los motivos eróticos, y «su prurito de desenvuelta manifestación pública de un autorretrato moral»:

[...] nótese bien que lo que ahí nos llama la atención no es la individualidad humana de su autor, sino la personalidad literaria que subyace a los poemas; sólo así se explica que el hechizo sobreviva tras diluirse muchas de las referencias que Rubén podía dar por sabidas, y que aparecen en sus versos a modo de sobreentendidos. A lo que apunta es principalmente a un ideal literario, al personaje que el autor quiere -en sus versos- ser. ${ }^{13}$

Efectivamente, la creación de un "yo" literario, así como la traslación de una experiencia individual al ámbito artístico mediante su adjudicación a un personaje lírico, han sido vistas repetidas veces como las actitudes fundamentales de la poesía moderna $^{14}$. Tal vez por eso, aunque Gimferrer reitera que Rubén Darío es el fundador de la modernidad en la poesía española ${ }^{15}$, le atribuye la inspiración fundamental de su primer libro a los modelos de la generación del 27 y a la poesía extranjera (Pound, Eliot, Perse $)^{16}$. Pero, aunque el poeta catalán considere que el magisterio poético de Rubén tiene que ver más con su sensibilidad que con sus prácticas formales concretas, no deja de ser sorprendente que considere el Modernismo como una escuela poética que, «distorsionando métrica y rima hasta sus últimas posibilidades, dictó la sentencia de muerte de ambas» ${ }^{17}$, en abierta contradicción con su propia práctica poética, y con la de buena parte de sus coetáneos.

De hecho, la admiración de Gimferrer por Rubén Darío se repite, aunque con variaciones sustanciales, en otro poeta del 70, Antonio Carvajal. Efectivamente, Carvajal reconoce también en Darío al poeta que aporta a la poesía del XIX «no sólo un nuevo

\footnotetext{
${ }^{13}$ Ibidem, p. xvii.

${ }^{14}$ Véase, por ejemplo, Robert Langbaum, La poesía de la experiencia. El monólogo dramático en la tradición literaria moderna (1957), trad. de Julián Jiménez Heffernan, Comares, Granada, 1996.

${ }^{15}$ Cfr. Pere Gimferrer, "Introducción", p. xviii.

${ }^{16}$ Cfr. Pere Gimferrer, Poemas (1963-1969), Visor, Madrid, 1979, p. 12.

${ }^{17}$ Pere Gimferrer, Antología de la poesía modernista, p. 9.
} 
tratamiento de la palabra, sino además, y lo que es más importante, un cambio profundísimo de sensibilidad ${ }^{18}$. Pero, en el caso de Carvajal, Rubén Darío no es sólo el fundador de una actitud moderna, sino también una referencia de estilo. La influencia del poeta nicaragüense resulta especialmente evidente en Tigres en el jardín, el primer libro de Antonio Carvajal, a cuyos sonetos el mismo autor les reconoce una «clara estirpe modernista» ${ }^{19}$. Aunque buena parte de la crítica recibió este libro como un retorno a formas de expresión barrocas, otros autores, como Emilio Miró, supieron ver su clara filiación con los sonetos de Rubén Darío, sobre todo en el léxico y en el empleo del alejandrino ${ }^{20}$. En la poesía de Antonio Carvajal, Rubén Darío es una presencia continua, desde el poema "Corónica angélica", en que se reivindica la «gracia achampanada» de los sonetos de Tigres en el jardín, que el poeta granadino quiso, como Rubén Darío, exprimida de «las uvas de Champaña/ para beber por Francia y en un cristal de España»" dando la estancia en Mallorca del poeta nicaragüense ${ }^{22}$, donde todavía «canta por la memoria un ruiseñor/ su verso azul y su canción profana» ${ }^{23}$.

Por su parte, Miguel d'Ors ha dejado constancia del deslumbramiento con que, a los catorce o quince años, leyó las Poesías completas de Manuel y Antonio Machado ${ }^{24}$, así como del afán reivindicativo que le llevó a estudiar la obra del mayor de los dos hermanos, eclipsado por la proliferación de ediciones y estudios

${ }^{18}$ Antonio Carvajal, "Jorge Guillén: naturaleza viva”, en Antonio Piedra; Javier Blasco Pascual (eds.), Jorge Guillén, el hombre y la obra. Actas del I Simposium Internacional sobre Jorge Guillén, Universidad de Valladolid-Fundación Jorge Guillén, Valladolid, 1995, p. 373.

${ }^{19}$ Antonio Carvajal, De métrica expresiva frente a métrica mecánica, Departamento de Lingüística General y Teoría de la Literatura de la Universidad de Granada, Granada, 1995, p. 130.

${ }^{20}$ Cfr. Emilio Miró, “Antonio Carvajal, Tigres en el jardín”, Ínsula n²70, mayo de 1969, p. 6.

${ }^{21}$ Rubén Darío, “Cyrano en España”, en Poesías completas, FCE, México, 1984, p. 257.

${ }^{22}$ Vid. Rubén Darío, "Epístola a la señora de Lepoldo Lugones”, Poesías completas, pp. 348-351.

${ }^{23}$ Antonio Carvajal, Los pasos evocados, Hiperión, Madrid, 2004, p. 89.

${ }^{24}$ Miguel d'Ors, Estudios sobre Manuel Machado, Renacimiento, Sevilla, 2001, pp. 7-8. 
sobre la obra de Antonio Machado a lo largo de buena parte de la posguerra española. La explicación de este olvido es bastante evidente, según d'Ors la expone en su "Reivindicación de Manuel Machado" de 1973:

Considerando la preocupación humanitaria, social y hasta política predominante en la poesía española desde 1944 hasta casi nuestros días, es obvio que Manuel, modernista primero y franquista después, tenía que ser postergado, mientras Antonio, regeneracionista, republicano, exiliado y finalmente víctima de la guerra, acaparaba las simpatías y era mitificado como santo laico, apóstol y mártir de la renovación nacional. En este punto se preguntará el lector qué tiene que ver todo esto con la poesía. La respuesta no me parece difícil: por influencia de la teoría literaria marxista, se llegó a creer que la calidad de un poema dependía, primordial o incluso únicamente, de su contenido (y, a veces, hasta de la conducta de su autor). Así se llevó a cabo una ilícita transferencia al campo artístico de unas valoraciones de índole sociopolítica y moral. ${ }^{25}$

Un aspecto en común, bastante significativo, entre los poetas modernistas y la generación del 70 es su rechazo hacia la poética vigente en su época, manifestado principalmente, en ambos casos, a través de la renovación formal del lenguaje lírico. En el caso de la generación del 70, esa poética precedente es la que dio lugar a las manifestaciones denominadas como "realismo social", "poesía comprometida", etc., ya superadas por buena parte de los poetas del 50. Pero la nueva generación fue la primera en declarar abiertamente la influencia recibida del Modernismo. Así, y ya en 1973, Miguel d'Ors destacaba en Manuel Machado su «sentido de la composición», su «capacidad para la descripción plástica», su «deslumbrante adjetivación», la «riqueza de su léxico»y su «instinto musical»; y, con unas palabras de indudable acierto profético, lo proponía como ejemplo y referencia para los poetas de su generación, así como para todos los que vendrían después:

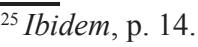


El primer centenario del nacimiento de Manuel viene a coincidir con los albores de una nueva etapa en la historia de la poesía española; etapa que está caracterizándose, entre otras cosas, por la superación de la estética contenutista y la consecuente revalorización del lenguaje. Quizá es éste un momento idóneo para releer a Manuel Machado y devolverle el puesto de honor que en justicia le corresponde dentro de nuestra lírica contemporánea. ${ }^{26}$

Esa "revalorización del lenguaje", que conlleva la atención al aspecto formal y técnico del poema, así como el subrayado de su carácter artificioso, tiene consecuencias en las prácticas métricas de los poetas del 70. Muchas de esas prácticas coinciden con los procedimientos renovadores más característicos en la métrica de los poetas modernistas, tal como los resume Dámaso Alonso en su artículo "Ligereza y gravedad en la poesía de Manuel Machado"27. El primero de estos procedimientos son las «rimas funambulescas», bien con nombres propios, bien con artículos, preposiciones, conjunciones y otros monosílabos al final del verso. Según Dámaso, el valor expresivo de estas rimas radica en que «realza la sensación de juego, y esto es lo que ha aprovechado la poesía humorística» ${ }^{28}$. En efecto, la ironía y el humor constituyen uno de los rasgos más significativos en la poesía del 70 , heredados de la generación anterior y cultivados de un modo más radical y con mayor frecuencia. Véase, por ejemplo, el comienzo del poema "Gradus ad Parnasum", de Miguel d'Ors, en que se parodia la solemnidad ingenua de los primeros poemas juveniles:

Son las cosas que pasan cuando uno es aún muy joven $\mathrm{y}$ cree en la luna y en la amistad y en Beethoven:

uno pone, con voz trascendental y pura, mayúscula a la palabra literatura y versifica con gesto de sacerdocio mojándose en las venas la pluma (mal negocio),

\footnotetext{
${ }^{26}$ Miguel d'Ors, Estudios sobre Manuel Machado, Renacimiento, 2000, p. 32.

${ }^{27}$ Dámaso Alonso, "Ligereza y gravedad en la poesía de Manuel Machado", en Dámaso Alonso, Poetas españoles contemporáneos, Gredos, Madrid, 1969, pp. 54-95.

${ }^{28}$ Ibidem, p. 54.
} 
y dice en sus poemas su intimidad desnuda

y resulta que ha dicho la de Alberti o Neruda.

$[\ldots]^{29}$

También la rima confiada a palabras monosílabas puede reforzar el tono humorístico y ligero de una composición. Es el caso de "Te diré", donde se describe la situación de un matrimonio en apuros económicos:

Pobres y de derechas. Te diré

-sin usar ni conjuro

ni bola de cristal ni posos de

té-, te diré ahora mismo, amor, lo que

veo en nuestro futuro:

veo, cómo decirlo, un no sé qué

que es duro y no es un duro.

Enigma un tanto oscuro, pero que a mí no me engaña, te lo juro:

amor, nos ha de dar más de un apuro el maldito parné.

$\mathrm{Y}$-esto puedes tenerlo por segurosin despertar ni un triste comité de apoyo en Comisiones o UGT ni la menor pintada en ningún muro. $[\ldots]^{30}$

A veces, el procedimiento de rimar nombres propios y monosílabos se combina con el empleo de palabras extranjeras; tal es el caso del fragmento octavo de La muerte en Beverly Hills, de Pere Gimferrer. En este fragmento, escrito en verso libre tendente al ritmo endecasílabico, se insertan unas estrofas en que el ritmo pasa a ser octosilábico, mezclando elementos extranjeros con motivos de nuestra lírica amorosa tradicional. El prurito de

\footnotetext{
${ }^{29}$ Miguel d'Ors, 2001 (Poesías escogidas), Cuadernos de Poesía Númenor, Sevilla, 2001, p. 170.

${ }^{30}$ Miguel d'Ors, Hacia otra luz más pura, Renacimiento, Sevilla, 1999, p. 57.
} 
cosmopolitismo y la heterogeneidad de ritmos y elementos culturales puede considerarse también afín al Modernismo:

Ella venía por la acera, desde el destello azul de Central Park. ¡Cómo me dolía el pecho sólo con verla pasar!

Sonrisa de azucena, ojos de garza, mi amor, entre el humo del snack te veía pasar yo.

¡Oh música, oh juventud, oh bullicioso champán!

(Y tu cuerpo como un blanco ramillete de azahar...)

$[\ldots]$

Todas las noches, en el snack, mi ojos febriles la vieron pasar.

Todo el invierno que pasé en New York mis ojos la buscaban entre nieve y neón.

$[\ldots]$

Se empañaban los cristales con el frío de New York. ¡Patinando en Central Park sería un cisne mi amor! ${ }^{31}$

Este tipo de rimas, que además refuerzan el culturalismo tan característico de Gimferrer, vuelven a aparecer en su último libro de poemas, Amor en vilo. En él encontramos rimando «Mallarmé» con «macramé»y «Lorca» con «ajorca», en "Hotel Axel"32, y «Alepo» con «cepo», en "By natural piety" ". En el caso de Antonio Carvajal, el juego con las posibilidades de la rima es una forma más de experimentación métrica, en la que, por ejemplo, puede confiarse la rima a palabras interrumpidas por la pausa versal. De esta manera, se busca el mismo efecto que Dámaso atribuía a las rimas funambulescas en el Modernismo, a saber, «una levísima violencia al lenguaje, un matiz que subraya, como un guiño sólo iniciado, la dicción, y que a la vez permite mayor fluidez al serpeante movimiento de la estrofilla» ${ }^{34}$. Véase, por ejemplo, el caso de "Vista de Badajoz al atardecer", donde se riman «si ve-/ hemente pájaro» con «escribe», «sobre-/ cogedora» con «cobre», y «trampa go-/ zosa» con «relámpago» ${ }^{35}$.

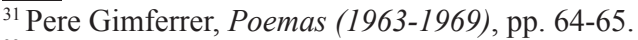

${ }^{32}$ Pere Gimferrer, Amor en vilo, Seix Barral, Barcelona, 2006, p. 56.

${ }^{33}$ Ibidem, p. 61.

${ }^{34}$ Dámaso Alonso, op. cit., p. 55.

${ }^{35}$ Antonio Carvajal, Extravagante jerarquía (Poesía 1968-1983), Hiperión, Madrid, 1983, pp. 75 y 77.
} 
La rima con palabras encabalgadas y monosílabos se combinan en el final de "Una perdida estrella", en el que «endemo-/ niado» rima con el precedente «extremo», y la rima con «fe» $\mathrm{y}$ «pie» se confía al relativo «que»:

[...] Todo sea por ella soportado, el endemoniado terror, la estrella fugaz, la melodía dura y bella de las monedas que suenan mejor que el verso. Hay quien no puede vivir sin luz ni fe.

Quien no ha visto la luz, que venga; hiede a cadáver, que el hombre está muerto, aunque en pie. ${ }^{36}$

Y el mismo juego se repite, con versos isométricos, en el poema "Huerta de San Vicente":

Rosas, todas; y no son la rosa. Todos los tilos, no la paz. El jazminero enlaza su canción con la cal, $[\ldots .]^{37}$

Otro de los rasgos señalados por Dámaso Alonso son las rimas interiores, practicadas por Manuel Machado según el modelo de Rubén Darío. Entre los poetas del 70, el uso de las rimas interiores obedece muchas veces al simple gusto por el verso sonoro y artificioso. Tal es el caso de Pere Gimferrer, en cuyo poema "Chiome bionde" encontramos los versos «como de Faetón vivirá el girasol», $\mathrm{o}$ «aplaca con el oro la placa de la nada» ${ }^{38}$, o estos tres versos de "Lipstick":

Son tus labios carnosos y me sanan la herida y me abren la herida que me sanan, partida mi vida por tus labios de mar en pleamar. ${ }^{39}$

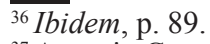

${ }^{37}$ Antonio Carvajal, Los pasos evocados, Hiperión, Madrid, 2004, p. 75.

${ }^{38}$ Pere Gimferrer, Amor en vilo, p. 22.

${ }^{39}$ Ibidem, p. 23.
} 
En ocasiones, el empleo de las rimas interiores llega hasta la paronomasia, como en "Hotel Alejandra (II)", donde encontramos «en que quedan mis ojos al ojeo»" ${ }^{40}$, o en "Envoi", con «por tu brocal y tu broquel que toca ${ }^{41}$. Otros autores, como Miguel d'Ors, prefieren limitar su uso a la evocación de efectos asociativos, visuales o sonoros. En "Fatum", poema que narra la vida de Antonio Machado, encontramos, por ejemplo, la siguiente enumeración: «no sabe que sus pasos felices por Sevilla/ -luz, patios, calles, cales- le acercan a Collioure $\rangle^{42}$, en que la rima interior favorece la asociación entre los elementos arquitectónicos y su revestimiento, tan típico de la ciudad natal de Machado. En otras ocasiones, la rima interior, ripio incluso, se convierte en imagen acústica de la realidad expresada por los términos rimados, como en el final del poema "Domingo":
[...] Pero no:
donde tú estás el mundo
se empeña en ser invierno
y noche y lunes. Como
un fado mal cantado,
se eterniza la lluvia
tras los cristales grises, llorabundos.
$[\ldots]^{43}$

Finalmente, la rima interior puede tener un valor onomatopéyico; es el caso del segundo verso este fragmento de "Atardecer de otoño en Sierra Nevada":
$[\ldots]$
Quietud. Sólo los saltos de las cabras
cruzan, con ecos secos, las serenas
alturas. Una paz de la que apenas
retienen un destello las palabras.
$[\ldots]^{44}$

\footnotetext{
${ }^{40}$ Ibidem, p. 28.

${ }^{41}$ Ibidem, p. 51.

${ }^{42}$ Miguel d'Ors, 2001 (Poesías escogidas), p. 82.

${ }^{43}$ Ibidem, p. 119.

${ }^{44}$ Ibidem, p. 223.
} 
Pero, sin duda, lo más característico del Modernismo es su empleo del verso alejandrino. Según Dámaso Alonso, este metro, verdadero favorito de los modernistas, manifiesta su herencia francesa en la tendencia «a establecer con mucha frecuencia extraños puentes, vínculos entre los dos hemistiquios», mediante el encabalgamiento entre ellos: «esto nos indica, desde ahora, que es criatura titubeante; que lo que busca es vaguedad, fluidez, imprecisión y, a la par, matiz» ${ }^{45}$. Un primer grado de este encabalgamiento lo constituiría, según Dámaso, la separación de los elementos de una unidad fonética. Este caso constituye también una práctica frecuente entre los poetas del 70. Así, por ejemplo, encontramos el sustantivo separado de sus adjetivos en los versos de Carvajal «y el amplio y rutilante fulgor de su perfume» ${ }^{46} \mathrm{e}$ «y todo es una sola naturaleza acorde»" ${ }^{47}$. En "Confidencias de un hijo de este tiempo", la conjunción inicial de una oración coordinada queda al final del primer hemistiquio, ligada a la vocal precedente: «para su exacto engaste; y declaro, humildemente» ${ }^{48}$, según esta medida:

pa-ra-sue-xac-toen-gas-tey-//de-cla-rohu-mil-de-men-te

Este tipo de encabalgamiento es también el más frecuente en otros autores. En los poemas de Pere Gimferrer encontramos ejemplos como «id más allá, muy lejos aún, hondo en la noche $\rangle^{49}$, «helada noche, ardiente noche, noche mía $\rangle^{50} \mathrm{y}$ 《cuando unos labios a otros labios temblando besan $»^{51}$. Y, con una sinalefa análoga al verso escandido de Carvajal, estos dos ejemplos: «si valía la pena o la vale. Tú, por quien» y «un arcángel o sauce o cisne o corcel de llama $\aleph^{52}$, medidos de esta forma:

si-va-lí-a-la-pe-nao-//la-va-le-tú-por-quien

un-ar-cán-gel-o-sau-ceo-//cis-neo-cor-cel-de-lla-ma

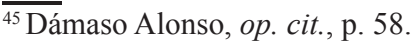

${ }^{46}$ Antonio Carvajal, Extravagante jerarquía (Poesía 1968-1983), p. 23.

${ }^{47}$ Ibid.,p. 28.

${ }^{48}$ Antonio Carvajal, De un capricho celeste, Hiperión, Madrid, 1988, p. 26.

${ }^{49}$ Pere Gimferrer, Poemas (1963-1969), p. 19.

${ }^{50}$ Ibidem, p. 20.

${ }^{51}$ Ibidem, p. 70.

${ }^{52}$ Ibidem, p. 20.
} 
En la obra de Miguel d'Ors, repiten el mismo caso los ejemplos «cuando había una letra pendiente, un libro abierto» ${ }^{53}$, «pero dentro la cal resplandeciente, el agua» y «afuera las palabras profundas, el progreso ${ }^{54}$.

Otro grado de encabalgamiento entre los hemistiquios sería, según Dámaso, la ruptura de un grupo de intensidad ${ }^{55}$. Ejemplo de esta práctica son los versos de Pere Gimferrer «el que fui entonces, sé tensarme y ser herido» ${ }^{56}$, «cuando tú amor a mi lado palidecías» ${ }^{57}$ y $\left\langle\right.$ mayestática como la espada del azul $»^{58}$. En la poesía de Miguel d'Ors, podrían mencionarse dos de los versos de "Gradus ad Parnasum", citados más arriba:

$$
\begin{aligned}
& \text { y-creen-la-luna-yen-0//laa-mis-tad-yen-Bee-tho-ven } \\
& \text { y-ver-si-fi-ca-con-0//ges-to-de-sa-cer-do-cio }
\end{aligned}
$$

Aunque nótese que, en el caso de Miguel d'Ors, este tipo de encabalgamientos tiene una finalidad expresiva, más allá del logro de un verso artificioso. En los ejemplos propuestos, el énfasis de la preposición al final de hemistiquio, pronunciada como terminación aguda, contribuye a reforzar la impresión de solemnidad ingenua en los ejercicios poéticos de juventud. Algo similar ocurre en el segundo de estos versos, de "Es doloroso estar tras el poema...":

$$
\begin{aligned}
& {[\ldots]} \\
& \text { igual que el tejedor al otro lado } \\
& \text { de su tapiz o como el farero en su torre } \\
& {[\ldots]^{59}}
\end{aligned}
$$

En efecto, la idea de aislamiento de un farero en su torre es reforzada por la separación del nexo precedente, justo antes de la cesura. También en el verso «como llegadas del recuerdo de

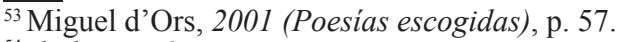

${ }^{54}$ Ibidem, p. 67.

${ }^{55}$ Cfr. Dámaso Alonso, op. cit., p. 61.

${ }^{56}$ Pere Gimferrer, Poemas (1963-1969), p. 20.

${ }^{57}$ Ibidem, p. 70.

${ }^{58}$ Pere Gimferrer, Amor en vilo, p. 27.

${ }^{59}$ Miguel d'Ors, 2001 (Poesías escogidas), p. 55.
} 
un recuerdo ${ }^{60}$ la pausa antes del sustantivo subraya su carácter de evocación imprecisa; y al hablar de las noches «sobresaltadas por ladridos y menudas/ carreras ratoniles $»{ }^{61}$, la preposición "por" como final agudo del primer hemistiquio expresa a la vez el sobresalto y la brusquedad del ladrido.

Como es lógico, el último grado de encabalgamiento entre los hemistiquios que distingue Dámaso Alonso es la tmesis o encabalgamiento léxico ${ }^{62}$. Por su carácter especialmente artificioso, son menos frecuentes los ejemplos que encontramos entre los poetas del 70. Al poema "Oda a Venecia ante el mar de los teatros", de Pere Gimferrer, pertenece el verso «aquel año de mi adolescencia perdida», cuya medida es la siguiente:

\section{a-quel-a-ño-de-mia-0/-do-les-cen-cia-per-di-da}

En el contexto del poema, este encabalgamiento tiene la virtud de subrayar, a la vez, el carácter artificioso del culturalismo de su autor, y la languidez propia de la adolescencia. Por lo que respecta a Miguel d'Ors, la práctica del encabalgamiento léxico está subordinada, una vez más, al logro de la expresividad. En el poema "Todo ocurrió para que tú nacieras" encontramos los versos «hexámetros desbaratados por el fuego»y «y sus males, desvaneciéndose en el tiempo» ${ }^{63}$, cuya escansión es la que sigue:

$$
\begin{aligned}
& \text { he-xá-me-tros-des-ba-0/-ra-ta-dos-por-el-fue-go } \\
& \text { y-sus-ma-les-des-va-0/-ne-cién-do-seen-el-tiem-po }
\end{aligned}
$$

En ambos casos, la tmesis contribuye a reforzar la noción del desbaratamiento y la desparición en el tiempo. Por último, en la evocación campestre de las "Elegías de Cotobade", encontramos el verso «y las sábanas extendidas en la hierba» ${ }^{64}$ cuyo encabalgamiento léxico sugiere la sacudida ondulada de las sábanas en el momento de ser extendidas sobre el suelo.

\footnotetext{
${ }^{60}$ Ibidem, p. 90 .

${ }^{61}$ Ibidem.

${ }^{62}$ Dámaso Alonso, op. cit., pp. 61-62.

${ }^{63}$ Miguel d'Ors, 2001 (Poesías escogidas), p. 79.

${ }^{64}$ Ibidem, p. 91.
} 
Como puede desprenderse de lo visto, la influencia del Modernismo está muy presente en la generación del 70, en lo que respecta tanto a su concepción poética como a sus prácticas métricas. Continuando el ejemplo de la generación precedente, los poetas del 70 conciben el poema como un hecho fundamentalmente lingüístico, dedicándole un interés primordial a los aspectos técnicos y formales. Son también muy conscientes de que el proceso de la escritura conlleva necesariamente una construcción y un distanciamiento respecto a sí mismos, y ello abre una importante vía de acceso al humor y la ironía. Por todo ello, su afinidad con el Modernismo es más que evidente, como lo demuestran además la declaración de sus preferencias que hemos recogido de tres de estos autores. Pero, además, los modelos modernistas han calado también en sus prácticas métricas, en lo que respecta sobre todo a la rima y al manejo del alejandrino. El cultivo de rimas con palabras poco usuales, nombres propios, monosílabos y términos extranjeros, así como las distintas maneras de encabalgar los dos hemistiquios del alejandrino, demuestran que la habilidad técnica y la consciencia del carácter artificioso del poema ocupan un lugar importante en su concepción de la poesía. 